\title{
CLINICOPATHOLOGICAL EVALUATION OF BENIGN BREAST DISORDERS IN DIFFERENT AGE GROUPS- A SINGLE CENTRE STUDY
}

\author{
Ranjit Chaudhary1, Chirag Shanti Dausage 2
}

${ }_{1}^{1}$ Associate Professor, Department of General Surgery, Peoples College of Medical Sciences and RC, Bhopal, Madhya Pradesh, India. ${ }^{2}$ Resident, Department of General Surgery, Peoples College of Medical Sciences and RC, Bhopal, Madhya Pradesh, India.

ABSTRACT
BACKGROUND
In the past few decades, breast health has been widely discussed owing to the increasing prevalence of breast cancer. This study
evaluated patients presenting with breast-related complaints to study the clinical patterns, which helped in the clinical diagnosis of
a benign breast disorder.

\section{MATERIALS AND METHODS}

This was a descriptive study conducted at People's College of Medical Sciences and Research Centre, Bhopal, between January 2014 and March 2015. The study population included both male and female patients of all age groups, presenting with complaints suggestive of benign breast disorder. Data was collected to note the demographic details and clinical characteristics.

\section{RESULTS}

A total of 65 patients were included in the study. The mean (SD) age of the patients was 42.48 years (12.25) and 60 (92.31\%) participants were females. The incidence of benign breast diseases was reported to be highest (43.08\%) in 21-30 yrs. age group. Breast lump $(n=39,60 \%)$ was the most common presentation. Overall, the right side of the breast was more commonly affected $(n=35,53.85 \%)$. A total of 27 (41.54\%) patients had upper inner quadrant affected. Most of the breast lumps were of sizes ranging from 3 to $3.9 \mathrm{~cm}(\mathrm{n}=20,51.28 \%)$. Fibroadenoma was the most common benign breast disorder in the present study.

\section{CONCLUSION}

Benign breast diseases are a common problem in females. A lump in the breast is the commonest presentation. Breast pain and nipple discharge are the other commonly encountered symptoms.

\section{KEY WORDS}

Benign Breast Diseases, Fibroadenoma, Fibrocystic Disease, Prevalence.

HOW TO CITE THIS ARTICLE: Chaudhary R, Dausage CS. Clinicopathological evaluation of benign breast disorders in different age groups- a single centre study. J. Evolution Med. Dent. Sci. 2018;7(51):5437-5439, DOI: 10.14260/jemds/2018/1203

\section{BACKGROUND}

In the past few decades, breast health has been widely discussed owing to the increasing prevalence of breast cancer. However, despite continuous efforts on raising the awareness of breast health, non-cancerous pathology of the breast is generally ignored. The frequency of benign lesion is almost 10-times more than malignant lesions.[1] The majority of benign breast disorders are generally minor aberrations of the normal processes of development and cyclical hormonal response. Around, nine out of 10 patients visiting with breast complaints have benign breast disorder and around 50\% of the women report to have benign breast disorder at some point in their life.[2]

Careful evaluation and early diagnosis may help in the successful management of the ailment and reduce the risk of morbidity and mortality. Ultrasonography, mammography, pathological examinations like core needle biopsy or fineneedle aspiration cytology (FNAC) during initial consultations may help in early diagnosis.

'Financial or Other Competing Interest': None.

Submission 06-11-2018, Peer Review 29-11-2018,

Acceptance 05-12-2018, Published 17-12-2018.

Corresponding Author:

Dr. Chirag Shanti Dausage,

Rampur, Jabalpur,

Madhya Pradesh,

India.

E-mail: chiragdausage@gmail.com

DOI: $10.14260 /$ jemds/2018/1203
Early evaluation and treatment may help to avoid unnecessary anxiety which could arise about breast cancer. It is also important to increase awareness on breast selfexamination, which will help to diagnose the disease at an early stage. In this report, results of a study are reported that evaluated patients presenting with breast-related complaints to study the clinical patterns which helped in clinical diagnosis of a benign breast disorder.

\section{MATERIALS AND METHODS}

This was a descriptive study conducted at People's College of Medical Science and Research Center, Bhopal, between January 2014 and March 2015. The study population included patients of either sex of all age group, presenting with complaints suggestive of benign breast disorder (e.g., breast lump, breast pain or a nipple discharge). Patients with a confirmed diagnosis of carcinoma breast or any other malignancies were excluded from the study.

The study was conducted according to the ethical principles of ICH-GCP. Written informed consent was obtained from each patient and/or guardian before their enrolment in the study. Following data were collected: age, marital status, parity and period of breastfeeding, relevant family history of breast diseases, hormone replacement therapy/contraceptive use. Additionally, each patient underwent a detailed examination of breast and axilla.

All patients underwent ultrasonography of bilateral breast and axilla. The mammography was done only in patients above 40 years of age. TruCut core needle biopsy 
was performed in patients with lumps to confirm the diagnosis. The final diagnosis was based on the histopathology report. All clinical findings were correlated to understand the clinical patterns in benign breast diseases.

\section{RESULTS}

A total of 65 patients presenting with symptoms of benign breast disorders were enrolled in this study. The mean (SD) age of the patients was 42.48 years (12.25) and the age ranged from 13 to 61 years. Based on age, patients were subdivided into five groups $(<20 ; 21$ to $30 ; 31$ to $40 ; 41$ to 50 ; $>50$ ) and evaluated the data to calculate the incidence of benign breast diseases in each age group. The incidence of benign breast diseases was reported highest (43.08\%) in 21 to 30 age group.

Based on signs and symptoms at presentation, patients were divided into six groups. The most common presentation of benign breast disease was recorded to be breast lump $(n=39,60 \%)$ which was further categorized into a lump with $(n=22,33.85 \%)$ and without pain $(n=17,26.15 \%)$. The other presenting features were pain in the breast $(n=12,18.46 \%)$ followed by nodular lesions or nodularity $(n=6,9.23 \%)$.

Overall, the right side of the breast was more affected $(n=35,53.85 \%)$. When the quadrants of affected breasts were evaluated, around 27 (41.54\%) patients had upper inner quadrant affected, followed by upper outer quadrant $(n=19$, 29.23\%), multi-quadrant, lower outer and lower inner ( $\mathrm{n}=5$ each, $7.69 \%)$, axilla ( $n=2,3.07 \%)$, entire breast and central $(\mathrm{n}=1$ each, 1.54\%). Based on specific types of benign breast disorders, the most commonly affected side of the breasts was noted. In breast abscess, the left breast was more commonly affected; whereas, in the case of fibroadenoma, the incidence of involvement of left breast was equal to that of the right breast. However, in fibroadenosis, right breast was more commonly involved. During local examination, the size of the palpable breast lump ranged from $1 \mathrm{~cm}$ to $11 \mathrm{~cm}$. Most of the breast lumps were of sizes ranging from 3 to $3.9 \mathrm{~cm}$ ( $\mathrm{n}=38,58.46 \%$ ) followed by those ranging from 2 to $2.9 \mathrm{~cm}$ $(\mathrm{n}=12,18.46 \%), \geq 5 \mathrm{~cm}(\mathrm{n}=10,15.38 \%), 1$ to $1.9 \mathrm{~cm}(\mathrm{n}=3$,

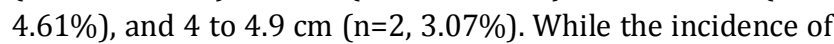
lumps of sizes 5 and more was significant (15.38\%), most of these were breast abscesses, galactoceles and a case of phyllodes tumour.

In present study, the benign breast disorders reported were fibroadenoma $(n=24)$, mastalgia $(n=12)$, fibroadenosis $(n=11)$, breast abscess $(n=6)$, gynecomastia $(n=5)$, phyllodes tumour $(\mathrm{n}=2)$, galactocele, antibioma, lactational mastitis, accessory breast and phyllodes tumour ( $\mathrm{n}=1$, each).

\begin{tabular}{|c|c|c|}
\hline Parameters & \multicolumn{2}{|c|}{ N= 65 } \\
\hline Age (Years), Mean (SD) & $42.48(12.25)$ \\
\hline Age, n (\%) & 15 & $(23.08)$ \\
\hline$<20$ & 28 & $(43.08)$ \\
\hline 21 to 30 & 11 & $(16.92)$ \\
\hline 31 to 40 & 6 & $(9.23)$ \\
\hline 41 to 50 & 5 & $(7.69)$ \\
\hline$>50$ & 60 & $(92.31)$ \\
\hline Sex, n (\%) & 60 & $(7.69)$ \\
\hline Female & 42 & $(64.62)$ \\
\hline Male & 28 & $(43.08)$ \\
\hline Married, n (\%) & \multicolumn{2}{|c|}{} \\
\hline History of Breast Feeding, n (\%) & \multicolumn{2}{|c|}{} \\
\hline \multicolumn{2}{|c|}{ Table 1. Demographic Characteristics }
\end{tabular}

\begin{tabular}{|c|c|c|}
\hline Main Complaint at Presentation, n (\%) & \multicolumn{2}{|c|}{ N= 65 } \\
\hline Lump in The Breast & 39 & $(60.00)$ \\
\hline With Pain & 22 & $(33.85)$ \\
\hline Without Pain & 17 & $(26.15)$ \\
\hline Only Pain & 12 & $(18.46)$ \\
\hline Nodular Lesions or Nodularity & 6 & $(9.23)$ \\
\hline Gynecomastia & 5 & $(7.69)$ \\
\hline Axillary Swelling & 2 & $(3.07)$ \\
\hline Discharge from Nipple & 1 & $(1.54)$ \\
\hline Table 2. Summary of Chief Complaints at Presentation \\
\hline
\end{tabular}

\section{DISCUSSION}

This descriptive study evaluated the clinical patterns of benign breast disorders. Results showed that benign breast disorder may present more commonly in specific age groups and it may follow specific clinical patterns. Though this may have regional and age variation, the present study provides useful information on benign breast disorder in an Indian setting.

\section{Breast development is generally divided into four stages-}

1) Quiescence.

2) Rapid growth and lobular development.

3) Cyclic changes in stromal and epithelial elements during menstruation and pregnancy.

4) Involution of lobules.[3]

However, any abnormality or deviation from normal physiological growth in the breast may lead to being described as a disorder. These abnormalities or deviation from normal physiological development/process in women may present as lump in the breast, nodular lesions or nodularity, swelling in the axilla, pain in the breast, discharge from nipple; however, in men they may present as enlarged breast (Gynecomastia), painless lump, thickening of skin around the breast, and discharge.

The incidence of benign breast lesions has been evaluated in several previous studies among patients visiting with breast complaints which have shown that the incidence of benign breast lesions ranges from $71.6 \%$ to $82.9 \% .^{[4-7]}$ In the present study, lump in the breast was the most common presentation in $60 \%$ of patients, of which more than half patients had a lump with pain; however, 12 patients presented with only pain with no other signs and symptoms, and five male patients presented with gynecomastia. These results were generally similar to previous studies where the presenting symptom was lump in the breast in 58\% (Tonape et al), [8] 58.06\% (Singh et al),[9] 72.35\% (Ratanachaikanont et al),[10] and $87.4 \%$ (Foncroft et al).[11]

In the present study, benign breast diseases was the highest in the age group of 21 to 30 years (43.08\%), which was consistent with previous study by Tonape et al (42\%) [8] and Das et al (45\%),[12] however, in another study by Kapur et al, the highest number of benign breast diseases were found in age group of 31 to 40 years (31.6\%), followed by 21 to 30 years (31.1\%) and 11 to 20 years (27.3\%).[13] In another study by Singh et al, aberrations in normal development and involution of the breast were highest reported in the age group 21 to 30 years and 31 to 40 years (36.36\% each) and breast lump was highest reported in 21 to 30 years group (52.77\%).[9] In another similar study by Kumar et al, aberrations in normal development and 
involution of the breast were highest reported in age group 41 to 50 years (44.44\%).[14]

When the location of the affected breast area was evaluated, the upper inner quadrant of the breast was found to be more $(41.54 \%)$ affected. In the previous report by Tonape et al, around $30 \%$ of patients had upper inner quadrant affected;[8] however, in another report by Singh et al, upper outer quadrant was more affected (27.42\%).[9] Overall, in the present study, the right side of the breast was more affected $(53.85 \%)$ and was consistent with the report by Singh et al (54.84\%). [9]

In the present study, the most common benign breast disorder was fibroadenoma (36.92\%), followed by mastalgia (18.46\%), and fibroadenosis (16.92\%). This was consistent with most of the previous studies, where the fibroadenoma was the common benign breast disorder- Tonape et al (42\%), Kapur et al (30\%),[13] Shashikala et al (37\%),[15] Bagale et al (30.08\%),[7] Kumar et al (36\%).[14] In contrast, a study from Nigeria showed the frequency of fibroadenoma ranging from $46.6 \%$ to $55.6 \%{ }^{[16,17]}$ In the present study, there were five $(7.69 \%)$ cases of gynecomastia, of which one case had bilateral gynecomastia. In the previous study by Bagale et al, 11 cases $(2.25 \%)^{[7]}$ were reported, other reports by Kapur et al $(1 \%)^{[13]}$ and Tonape et al (8\%) ${ }^{[8]}$ had different results.

Authors also acknowledge the following limitations of the study. First, the study was single-center and second, the sample size was comparatively low. Hence, care should be taken when generalizing the results.

\section{CONCLUSION}

Benign breast diseases are a common problem in females.

A lump in the breast is the commonest presentation. Breast pain and nipple discharge are the other commonly encountered symptoms.

Benign breast disorders may be more prevalent in specific age groups and may have specific clinical patterns.

Ultrasound and TruCut biopsy may help in establishing an early diagnosis.

One cannot overemphasise the importance of TruCut biopsy as a preliminary diagnostic test in palpable breast lumps. In expert hands, the results show a high degree of correlation with the final histopathology report.

\section{REFERENCES}

[1] Guray M, Sahin AA. Benign breast diseases: classification, diagnosis, and management. Oncologist 2006;11(5):435-49.

[2] Bhargava GS, Gupta A, Grover A, et al. Benign breast disorders: rural Punjab population study compared with urban population studies. Int Surg J 2015;2(4):629-33.
[3] Kayes SG. Human toxocariasis and the visceral larva migrans syndrome: correlative immunopathology. Chem Immunol 1997;66:99-124.

[4] Amr SS, Sa'di, ARM, Ilahi F, et al. The spectrum of breast diseases in Saudi Arab females: a 26 year pathological survey at Dhahran health center. Ann Saudi Med 1995;15(2):125-32.

[5] Kulkarni S, Vora IM, Ghorpade KG, et al. Histopathological spectrum of breast lesions with reference to uncommon cases. Obstet Gynecol India 2009;59(5):444-52.

[6] Man M, Salahuddin O, Azhar M, et al. Breast diseases: spectrum in Wah Cantt: POF Hospital experience. Professional Med J Sep 2010;17(3):366-72.

[7] Bagale P, Dravid NV, Bagale S, et al. Clinicopathological study of benign breast diseases. Int J Health Sci Res 2013;3(2):47-54.

[8] Tonape TP, Tulsian AR, Gope DD, et al. A study of clinical patterns in benign breast disorders. Int Surg J 2018;5(2):518-22.

[9] Singh SK, Ahmad KN, Pankaj D, et al. Benign breast lesions in a teaching hospital in rural Bihar. IJSS Journal of Surgery 2016;2(1):6-10.

[10] Ratanachaikanont T. Clinical breast examination and its relevance to diagnosis of palpable breast lesion. J Med Assoc Thai 2005;88(4):505-7.

[11] Foxcroft LM, Evans EB, Hirst C, et al. Presentation and diagnosis of adolescent breast disease. Breast 2001;10(5):399-404.

[12] Das N, Debbarma A, Debbarma G. A clinicopathological study of benign breast diseases in rural population. Int J Res Med Sci 2014;2(3):1067-9.

[13] Kapur V, Walia BS, Singh S, et al. Clinicopathological study of various breast diseases in different age groups. Int J Curr Res Med Sci 2017;3(11):16-22.

[14] Kumar N, Monika K. Benign breast diseases in tertiary center in North Bihar: a clinico-pathological study. Int J Sci Stud 2016;4(2):56-9.

[15] Shashikala V, Rani SPB, Victor AJ. Clinicopathological study of benign breast diseases. Int J Biomed Adv Res 2016;7(9):424-7.

[16] Adesunkami AR, Agbakwuru EA. Benign breast disease at Wesley Guild Hospital, Ilesha, Nigeria. West Afr J Med 2001;20(2):146-51.

[17] Ihekwaba FN. Benign breast disease in Nigerian women: a study of 657 patients. J R Col Surg Edinb 1994;39(5):280-3. 